\title{
Sales Management System in Grocery Store Mobile Phone Based
}

\section{Sistem Manajemen Penjualan di Toko Kelontong Berbasis Ponsel}

\author{
Mohammad Fahrizal Ardiyansyah ${ }^{1}$, Arief Senja Fitrani ${ }^{2}$ \\ \{fhrzldian@gmail.com ${ }^{1}$, asfjim@umsida.ac.id ${ }^{2}$ \}
}

Universitas Muhammadiyah Sidoarjo, Indonesia ${ }^{1}$, Universitas Muhammadiyah Sidoarjo, Indonesia ${ }^{2}$

\begin{abstract}
A grocery store is a small shop that is easily accessible to the public and is located on a busy street, gas station, train station or in a densely populated urban or residential area. Most of these types of shops are traditionalin nature, where buyers cannot freely pick up their own goods, usually there is a dividing screen in the form of a window or shelf. If you pay attention, actually the goods sold in grocery stores are almost similar to those sold in supermarkets such as Alfamart or Indomart, it's just that the minimarkets are modern. People often refer to this shopas a grocery store. Among the many minimarkets and modern shops in Sidoarjo, it turns out that there is a grocery store whose building is still standing up to this day, namely An Nur Shop. This shop is located in Jambangan Candi Sumokali, Sumokali, Jambangan, Kec. Candi, Sidoarjo Regency, East Java 61271, Toko An Nur is a grocery store that was founded in 1990. An Nur shop has very many customers so that the stock of merchandise is often short, this makes An Nur shop troublesome in bringing in merchandise, so it requires sales of goods to arrive the merchandise sold. Based on the problems faced, through this research activity, the EKELONTONG application is proposed. Through the E-KELONTONG application, it will be easier for An Nur Stores to bring in products through sales withthe E-KELONTONG application.

The creation of this E-KELONTONG application uses a way of collecting data by retrieving data directly from an Annur grocery store, interviewing the store owner. The software used to build this E-GROCERY application is using Android Studio 3.5 and Xampp server.
\end{abstract}

Keywords - Grocery store, The E-KELONTONG Application

\begin{abstract}
Abstrak. Toko kelontong adalah toko kecil yang mudah diakses umum dan terletak dijalan yang ramai, SPBU, Stasiun kereta api atau dipemukiman padat penduduk diperkotaan atau diperumahan.Toko jenis ini kebanyakan bersifat tradisional dimana pembeli tidak bisa leluasa mengambil barang sendiri biasanya ada sekat pemisah berupa etalase atau rak. Jika diperhatikan sebenarnya barang yang dijual ditoko kelontong hampir mirip dengan yang djualdiminimarket seperti Alfamart atau Indomart hanya saja minimarket sudah modern. Masyarakat sering juga menyebut Toko ini sebagai toko sembako. Di antara maraknya minimarket dan toko-toko modern di Sidoarjo, ternyata ada sebuah toko kelontong yang bangunannya masih berdiri tegak hingga saat ini, yaitu Toko An Nur. Toko ini berada diJambangan Candi Sumokali, Sumokali, Jambangan, Kec. Candi, Kabupaten Sidoarjo, Jawa Timur 61271, Toko An Nur adalah sebuah toko kelontong yang didirikan pada tahun 1990. Toko An Nur memiliki pelanggan yang sangat banyak sehingga persediaan stok barang dagangan sering kekurangan, hal ini membuat repot Toko An Nur dalam mendatangkan barang dagangan, sehingga membutuhkan sales barang untuk mendatangan barang dagangan yang dijual. Berdasarkan permasalahan yang dihadapi tersebut, melalui kegiatan penelitian ini maka diusulkan aplikasi E- KELONTONG. Melalui aplikasi E- KELONTONG akan dapat mempermudah Toko An Nur untuk mendatangkan produk melalui sales dengan aplikasi E-KELONTONG.

Pembuatan aplikasi E-KELONTONG ini menggunakan cara pengumpulan data dengan mengambil data langsung daritoko kelontong An nur, mewancarai pemilik toko. Software yang digunakan untuk membangun aplikasi EKELONTONG ini yaitu mengguanakan Android Studio 3.5 dan Xampp server.
\end{abstract}

Kata kunci - Toko Kelontong, Aplikasi E-kelontong. 


\section{PENDAHULUAN}

Toko kelontong adalah toko kecil yang mudah ditemui dan terletak dijalan yang ramai, kelontong sendiri umumnya menjual kebutuhan sehari hari seperti bahan sandang dan pangan.Toko jenis ini kebanyakan bersifat tradisional walapun begiu sebenarnya barang yang dijual ditoko kelontong hampir mirip dengan yang djual diminimarket seperti Alfamart atau Indomart hanya saja minimarket sudah modern. Masyarakat sering juga menyebut Toko ini sebagai toko sembako. [3]

Di antara maraknya minimarket dan toko-toko modern di Sidoarjo, ternyata ada sebuah toko kelontong yang bangunannya masih berdiri tegak hingga saat ini, yaitu Toko An Nur. Toko ini berada di Jambangan Candi Sumokali, Sumokali, Jambangan, Kec. Candi, Kabupaten Sidoarjo, Jawa Timur 61271, Toko An Nur adalah sebuah toko kelontong yang didirikan pada tahun 1990. [1]

Toko An Nur memiliki pelanggan yang sangat banyak sehingga persediaan stok barang dagangan sering kekurangan, hal ini membuat repot Toko An Nur dalam mendatangkan barang dagangan, sehingga membutuhkan sales barang untuk mendatangan barang dagangan yang dijual. [1]

Berdasarkan permasalahan yang dihadapi tersebut, melalui kegiatan penelitian ini maka diusulkan aplikasi E-KELONTONG. Melalui aplikasi E- KELONTONG akan dapat mempermudah Toko An Nur untuk mendatangkan produk melalui sales dengan aplikasi E-KELONTONG. [2]

\section{A. Lokasi dan Waktu Penelitian}

\section{METODE}

Dalam menyelesaikan penelitian ini, penulis melakukan penelitian di Toko An Nur yang berada di Jambangan Candi Sumokali, Sumokali, Jambangan, Kec. Candi, Kabupaten Sidoarjo, Jawa Timur 61271,

\section{B. Bahan dan Alat Penelitian}

Sistem Manajemen Sales Pada Toko Kelontong Berbasis Mobile Phone (E-KELONTONG)ini memerlukan perangkat keras dan perangkat lunak. Bahan dan alat yang dibutukan dalam merancang system informasi tersebut adalah:

\section{Bahan Penelitian}

Bahan-bahan yang digunakan untuk merancang Sistem Manajemen Sales Pada Toko Kelontong Berbasis Mobile Phone (E-KELONTONG) adalah:

1. Buku referensi android

2. Jurnal yang berhubungan dengan judul proposal yang penulis buat

\section{Alat Penelitian}

Alat-alat penelitian yang akan digunakan untuk Sistem Manajemen Sales Pada Toko Kelontong Berbasis Mobile Phone (E-KELONTONG) :

1. Perangkat Keras Komputer dengan spesifikasi:

$\begin{array}{ll}\text { Processor } & \text { : Core i3 4005U-1.7Ghz } \\ \text { RAM } & : 4 G B \\ \text { VGA } & \text { : Vga Intel HD 4400, } \\ \text { Layar } & \text { : LED 13.3" } \\ \text { Hard Disk } & \text { : HDD 500GB SATA }\end{array}$

2. Software.

Windows 764 Bit

Android Studio 3.5

Xampp Server

\section{Tahap Pengumpulan Data}

Untuk mendapatkan informasi, data-data penunjang serta teori dalam penyusunan proposal skripsi ini, maka diperlukan teknik pengumpulan data. Adapun teknik yang digunakan antara lain:

1. Pengamatan (Observasi)

Merupakan metode pengumpulan data yang diperoleh dengan melakukan pengamatan dan pencatatan data dari sumber

2. Studi Pustaka (Literatur)

Merupakan metode pencarian data buku, browsing internet atau literatur-literatur yang berkaitan dengan data yang dibutuhkan dalam peneletian dan pembuatan aplikasi berbasis Android. [4] 
D. Perancangan dan Pembuatan Sistem Untuk Aplikasi

1. Blog Diagaram

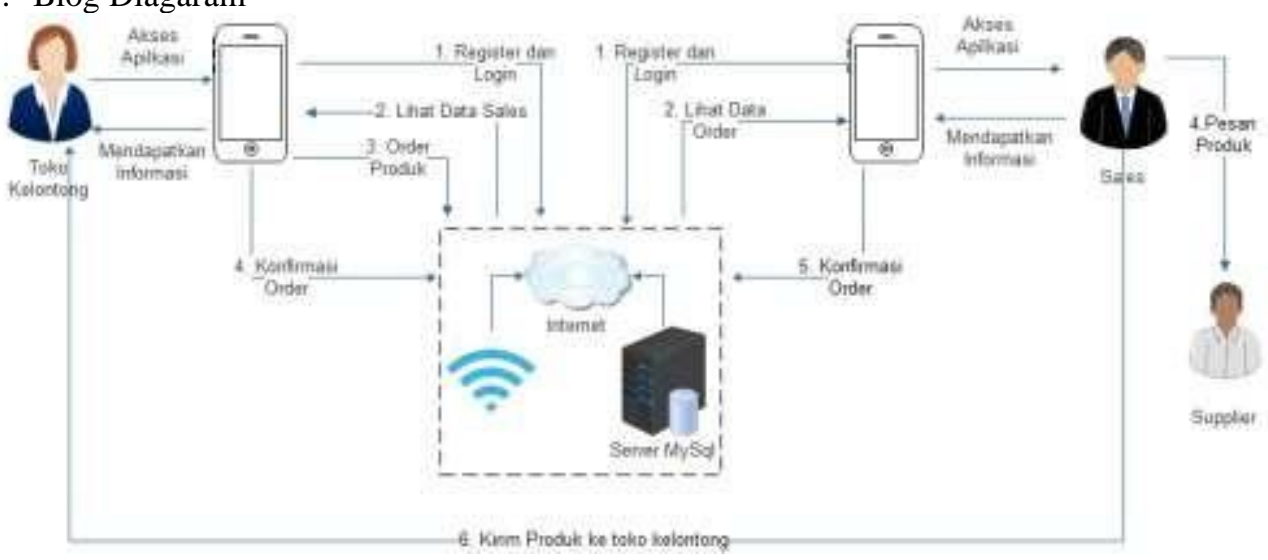

Gambar 3.1 Blog Diagram

Pada bagian ini akan menjelaskan mengenai blog diagram dari aplikasi :

A. Toko kelontong

1. Toko Kelontong Register Kumudian Login Aplikasi

2. Toko Kelontong melihat list sales pada aplikasi untuk mencari produk yang akan dijual di toko kelontong

3. Toko Kelontong order produk ke sales

4. Toko kelontong konfirmasi kedatangan produk yang dikirim sales

B. Sales

1. Sales register dan login diaplikasi E-Kelontong

2. Sales melihat order produk yang diorder oleh toko kelontong

3. Sales pesan produk ke supplier

4. Sales konfirimasi bahwa order akan diproses oleh sales

5. Sales mengirim produk ke Toko kelontong

2. Use Case Diagram

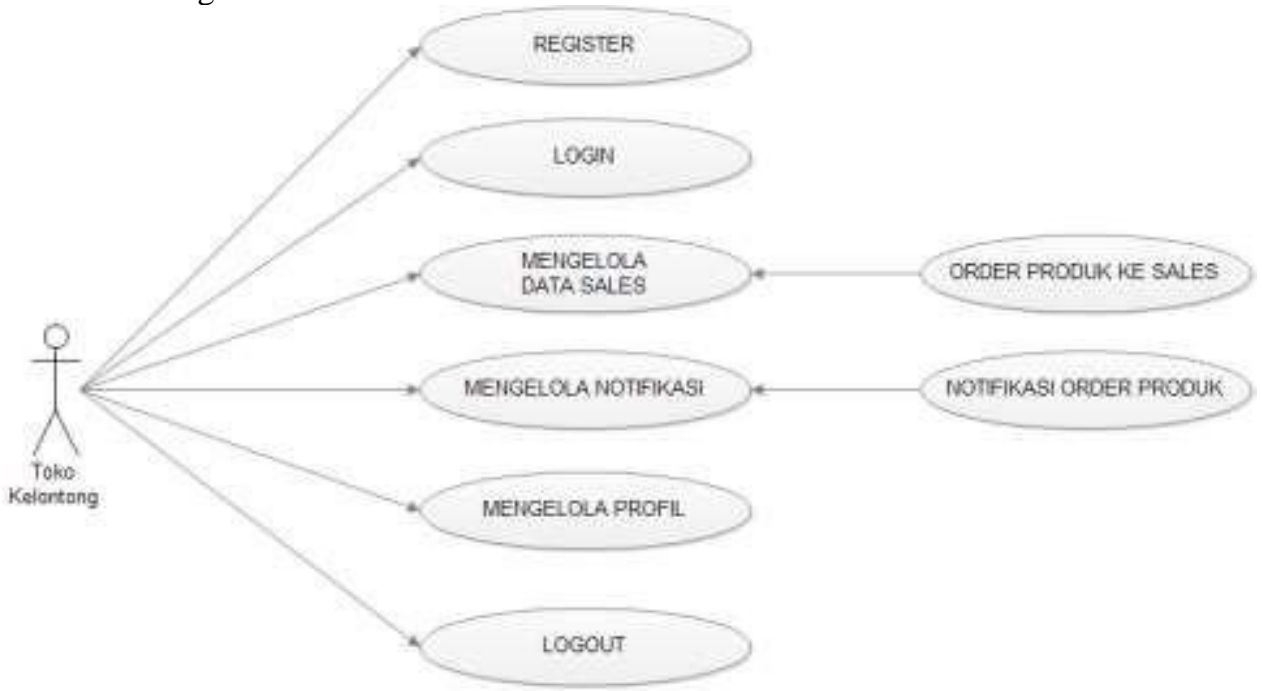

Gambar 3.2 Uses Case Diagram Toko Kelontong

Pada use case diatas, actornya adalah toko kelontong dimana tugas untuk membuka halaman register, Login, mengelola data sales, melola notifikasi dan mengelola profil. [7] 


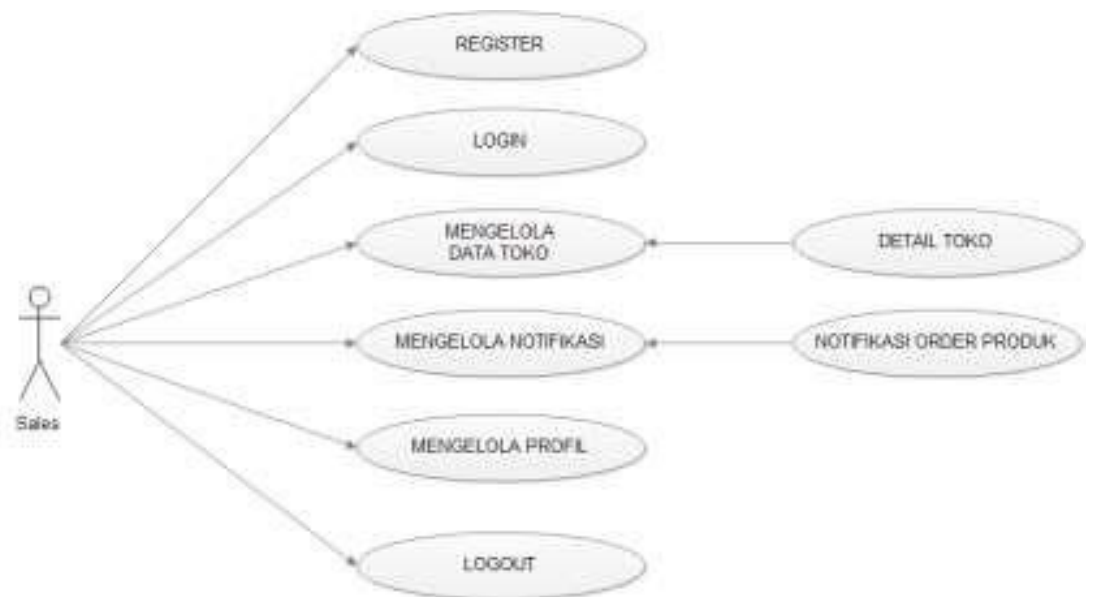

Gambar 3.3 Uses Case Diagram Sales

Pada use case diatas, actornya adalah Suplier dimana tugas untuk membuka halaman register, Login, mengelola data toko, melola notifikasi dan mengelola profil. [7]

3. Squence Diagram

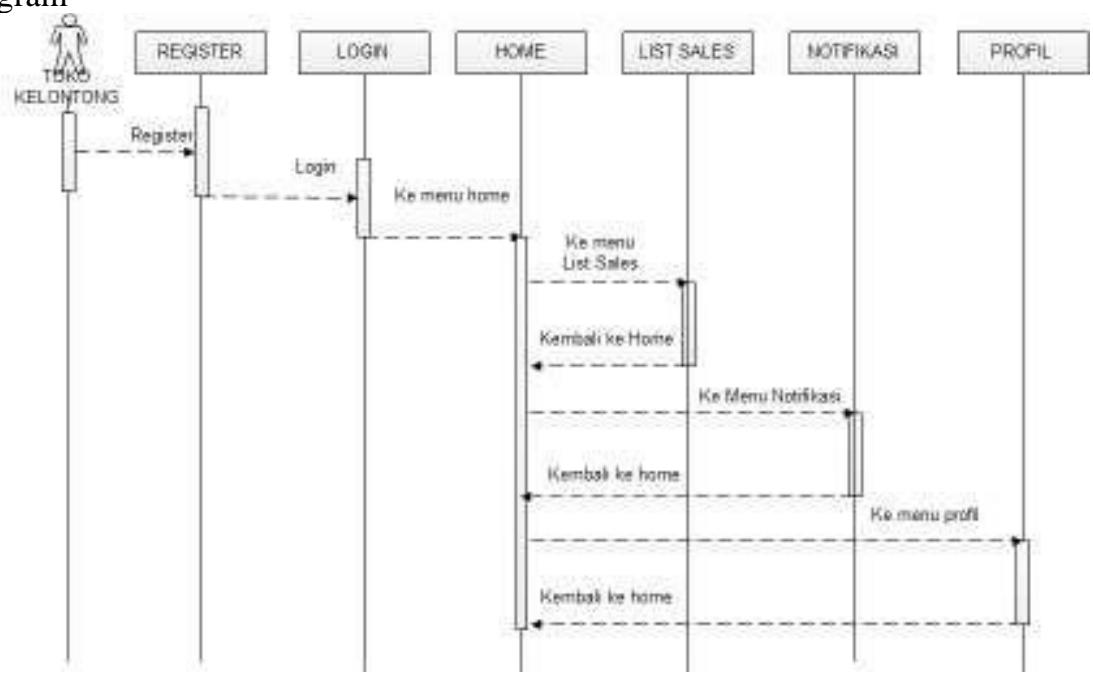

Gambar 3.4 Squence Diagram Toko Kelontong

Berdasarkan gambar diatas sequence diagram Toko Kelontong yang diusulkan terdapat:

1 (satu) aktor yang dapat melakukan kegiatan yaitu : mengoprasikan aplikasi.

6 (enam) lifeline yang berbeda yaitu Register, login, home, list sales, notifikasi, profil [7]

4. Class Diagram

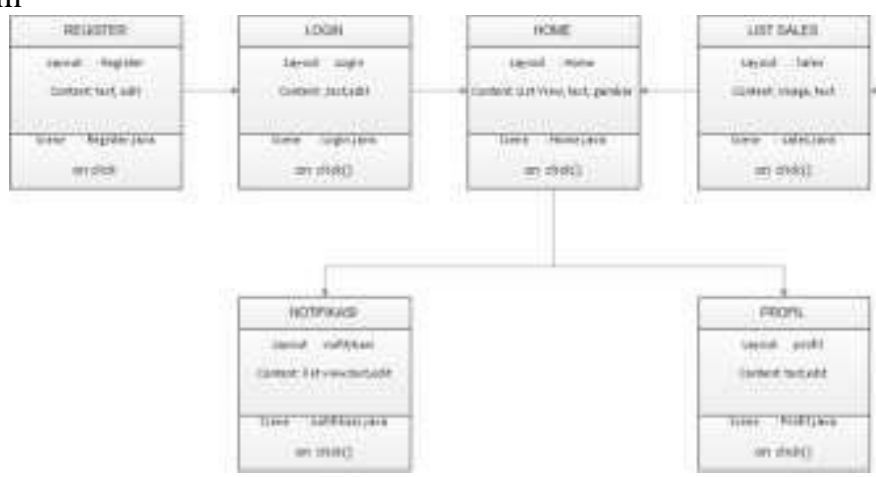

Gambar 3.5 Class Diagram Toko Kelontong 
Class diagram Toko Kelontong diatas menggambarkan struktur dan deskripsi class, package dan objek beserta hubungan satu sama lain seperti register, login, home, list sales, order produk, notifikasi, profil [7]

5. Activity Diagram

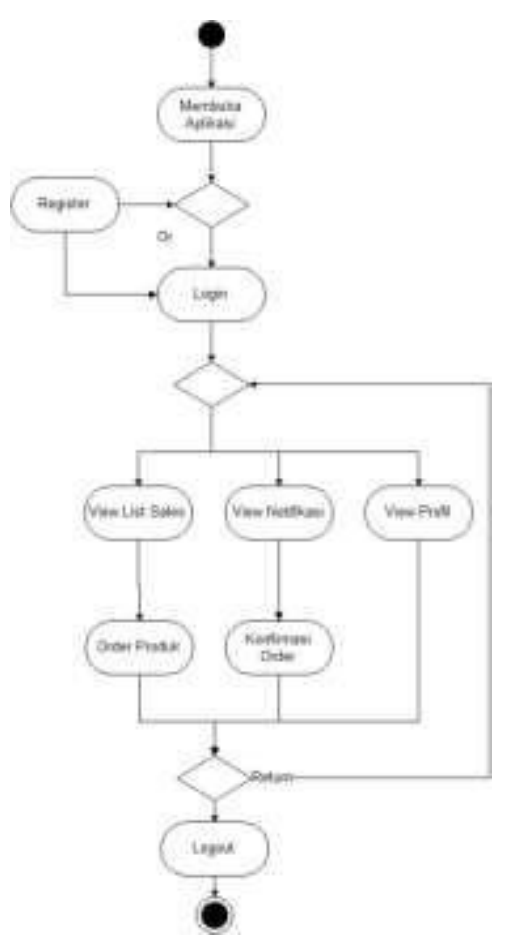

Gambar 3.6 Activity Diagram

Gambar diatas merupakan Activity Diagram, proses diatas memiliki kegiatan sebagai berikut :

1. Login sebagai objeck awal

2. 3 Activity Diagram menggambarkan proses system tersebut seperti membuka view list sales, nofikasi, profil

3. Node keluar adalah proses keluar system jika yam aka aplikasi akan tertutup jika tidak maka aplikasi akan kembali

4. Node terakhir untuk mengkahir aplikasi

\section{Struktur Tabel}

1. Tabel users

Tabel user digunakan untuk menyimpan data user

Tabel 3.1 users

\begin{tabular}{|l|l|l|}
\hline Field & Type dan Size & Keterangan \\
\hline id_users & $\operatorname{int}(11)$ & Id users (PK) \\
\hline nama & varchar(50) & Nama \\
\hline alamat & varchar(100) & Alamat \\
\hline no_telp & Varchar(15) & Nomer Telepon \\
\hline foto & varchar(100) & foto \\
\hline username & varchar(50) & username \\
\hline password & varchar(10) & Password \\
\hline level & Varchar(20) & Level login \\
\hline Level & Varchar(10) & Level login \\
\hline
\end{tabular}

2. Tabel pesan

Tabel pesan digunakan untuk menyimpan data pesan

\begin{tabular}{|l|l|l|}
\hline \multicolumn{2}{|c}{ Tabel 3.2 pesan } \\
\hline Field & Type dan Size & Keterangan \\
\hline
\end{tabular}


Procedia of Engineering and Life Science Vol. 1. No. 1 March 2021

Seminar Nasional \& Call Paper Fakultas Sains dan Teknologi (SENASAINS $1^{\text {st) }}$

Universitas Muhammadiyah Sidoarjo

\begin{tabular}{|l|l|l|}
\hline id_pesan & $\operatorname{int}(11)$ & $\underline{\text { Id users (PK) }}$ \\
\hline no_pesan & varchar(10) & Nomer pesan \\
\hline isi_pesan & text & $\underline{\text { Isi pesan }}$ \\
\hline id_dari & $\operatorname{int}(11)$ & $\underline{\text { Pesan pengirim (FK) }}$ \\
\hline id_ke & $\operatorname{int}(11)$ & $\underline{\text { Pesan penerima (FK) }}$ \\
\hline tanggal & timestamp & $\underline{\text { Tanggal }}$ \\
\hline status & varchar(10) & $\underline{\text { Status pesan }}$ \\
\hline
\end{tabular}

3. Tabel Barang

Tabel barang digunakan untuk menyimpan data barang

\begin{tabular}{|l|l|l|}
\hline \multicolumn{2}{|c|}{ Tabel 3.5 barang } \\
\hline Field & Type dan Size & Keterangan \\
\hline id_barang & $\operatorname{int}(11)$ & $\underline{\text { Id barang }(\mathrm{PK})}$ \\
\hline id_barang & $\operatorname{vachar}(100)$ & $\underline{\text { Nama produk barang }}$ \\
\hline
\end{tabular}

\section{Perancangan Inteface}

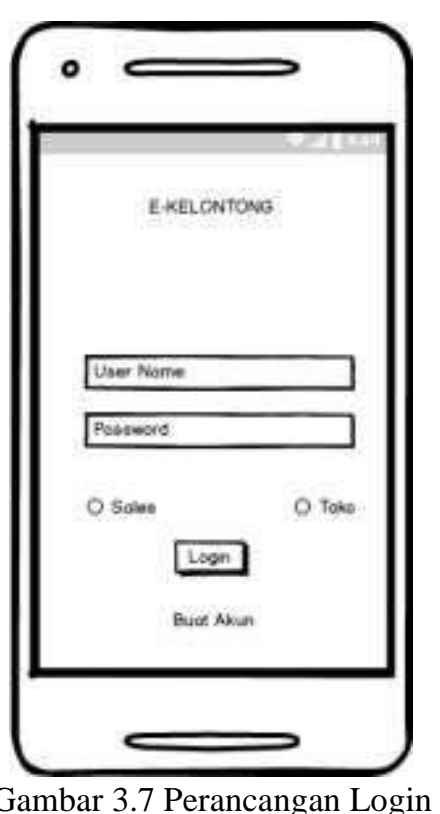


Procedia of Engineering and Life Science Vol. 1. No. 1 March 2021

Seminar Nasional \& Call Paper Fakultas Sains dan Teknologi (SENASAINS 1 ${ }^{\text {st }}$ )

Universitas Muhammadiyah Sidoarjo

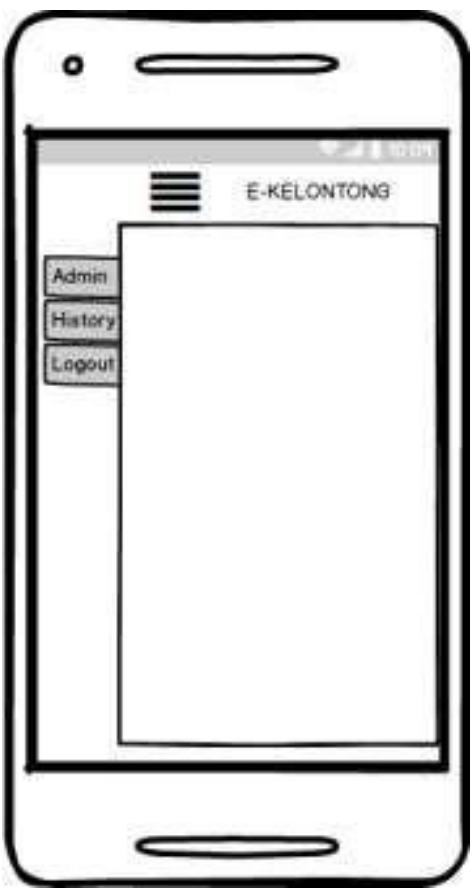

Gambar 3.8 Perancangan Menu Toko Kelontong

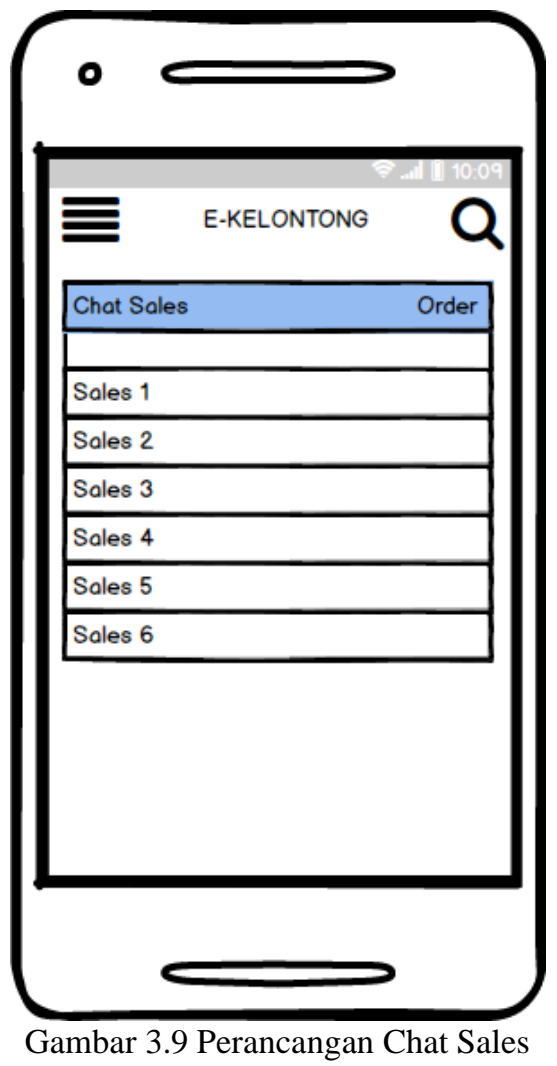




\section{A. Hasil Penelitian}

\section{HASIL PENELITIAN DAN PEMBAHASAN}

Pada Penelitian ini akan dijelaskan bahwa yang dikerjakan oleh aplikasi E-Kelontong adalah:

1. Halaman admin atau toko berfungsi untuk user toko yang ingin memesan produk yang dijual oleh sales, berikut ini menu dalam halaman admin :
1. Home
2. History
3. Logout

2. Halaman sales berfungsi untuk user sales yang mengkonfirmasi pesanan kepada sales tersebut dan mengirim produk yang dijual sales tersebut, berikut ini menu dalam halaman sales :
1. Home
2. History
3. Profile

\section{B. Pembahasan}

1. Halaman Admin atau Toko

1. Login dan Register

Login berfungsi untuk keamanan aplikasi yang digunakan oleh user admin, untuk menjalakan fungsi login ini user harus memasukan username dan password yang dimiliki kemudian tekan login untuk memproses login [5]

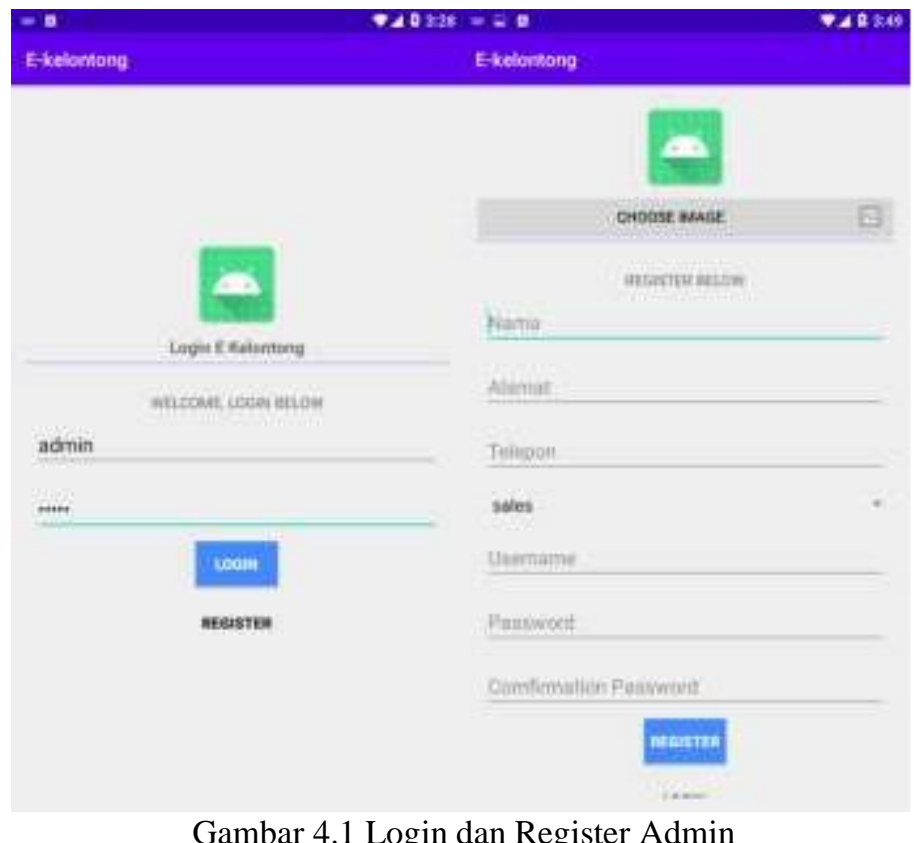

Gambar 4.1 Login dan Register Admin

Sedangakan Register berfungsi untuk user admin yang belum memiliki akun login, untuk mejelakan fungsi register ini user harus memasukan nama, alamat, no telp, username dan password setelah mengisi data itu semua tekan register untuk menyimpan dan mengirim data ke server. [6]

2. Menu Admin 


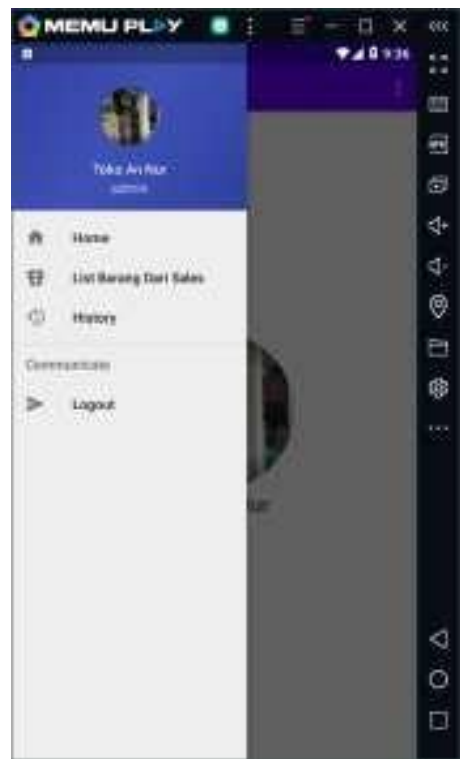

Gambar 4.2 Menu Admin

Menu admin berfungsi untuk menampilkan menu yang dapat diakses oleh admin, menumenuyang dapat diakases oleh admin adalah menu home, history dan logout, yang pejelasanya ada dibawah ini. [6]

3. Home Admin

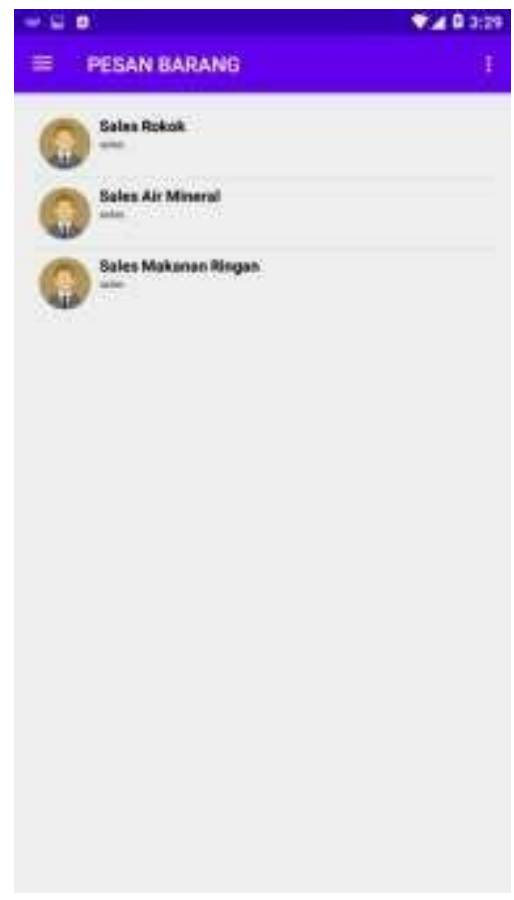

Gambar 4.3 Home Admin

Home admin berfungsi untuk menampilkan data sales dalam bentuk listview dihalaman ini data yang ditampilkan adalah nama sales, dan level sales, dan untuk memesan produk yang dijual sales, user admin dapat memilih salah satu sales, setelah memilih salah satu sales makan akan tampil form pesanan seperti dibawah ini. 


\section{A. Kesimpulan}

\section{KESIMPULAN}

Kesimpulan dari skripsi yang berjudul : "Sistem Manajemen Sales pada toko kelontong berbasis Mobile Phone (E-Kelontong)" ini adalah sebagai berikut :

1. Dapat menbantu memudahkan toko kelontong dalam mengorder barang dari sales.

2. Dengan adanya aplikasi ini pengguna dapat mengurangi kesalahapahaman antara pihak toko dan sales.

3. Apilkasi yang dibuat berbasis android untuk mempermudah dalam penggunaannya.

\section{REFERENSI}

[1] Buyens, Jim. 2001. Web Database Development. Elex Media Komputindo. Jakarta

[2] Hermawan S, Stephanus. 2011.“Mudah Membuat Aplikasi Android”.Yogyakarta : Andi OffsetJogiyanto H.M , 1990 Analisis dan Desain Sistem Informasi. Yogyakarta: Andi Offset.

[3] Kamus Besar Bahasa Indonesia. Pengertian Warung Kelontong [online]. Tersedia: http://kamus.sabda.org/kamus/warung/2011/6/24 [19 Februari 2017]

[4] Kusrini M.Kom, 2007. Strategi Perencanaan dan Pengelolaan Basis Data: Andi Offset.

[5] Nazaruddin, Safaat H, 2014 , Pemrograman Aplikasi Mobile Smartphone dan Tablet PC Berbasis Android. Bandung:Informatika.

[6] Safaat, Nazruddin. 2011 Pemprograman aplikasi Mobile Smartphone dan Tablet PC berbasis Android, Informatika,Bandung

[7] Tulach, J. 2008. Practical API Design : Confessions of a Java FrameworkArchitect. United States of America:Apress. 